\title{
A multivariate regional test for detection of trends in extreme rainfall: the case of extreme daily rainfall in the French Mediterranean area
}

\author{
L. Neppel ${ }^{1}$, N. Pujol ${ }^{1}$, and R. Sabatier ${ }^{2}$ \\ ${ }^{1}$ Université Montpellier II, Maison des Sciences de l'Eau, UMR 5569 HydroSciences Montpellier \\ UM2/UM1/CNRS/IRD - cc MSE, 34095 Montpellier cedex 5, France \\ ${ }^{2}$ Laboratoire de physique industrielle et traitement de l'information, UFR Pharmacie, UM1 et EA 2415, \\ 641 avenue Gaston-Giraud, 34093 Montpellier cedex 5, France
}

Received: 17 December 2009 - Revised: 20 February 2010 - Accepted: 19 March 2010 - Published: 8 February 2011

\begin{abstract}
In this paper we present a multivariate regional test we developed for the detection of trends in extreme rainfall, which takes into account the spatial dependence between rainfall measurements with copula functions. The test is based on four steps. It was applied to a set of 92 series of Annual Daily Maxima (ADM) rainfall in the French Mediterranean area, sampled during the 1949-2004 observation period. The results show a low significant trend, concerning mainly the mountains area in the west part of the French Mediterranean region. The position's parameters of the ADM rainfall probability distribution functions present a low but significant increasing trend of about $5 \%$ to $10 \%$, the same increase as that observed in ADM rainfall quantiles in the last 56 years. Further work is needed to understand if this significative trend is related to the global climate change or to the natural variability of Mediterranean climate.
\end{abstract}

\section{Introduction}

The effect of human activity on climate and global warming is now accepted by the whole scientific community (IPCC, 2007). In the context of global warming, a major question concerns its consequences for extreme events. One way to answer this question is to analyse different scenarios of extreme events produced by climate models. However, such scenarios depend on the model and the spatiotemporal scales

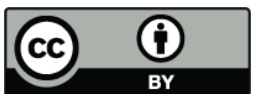

Correspondence to: L. Neppel

(neppel@msem.univ-montp2.fr) used often do not fit the dynamics of extreme events. As global warming started at the beginning of the 20th century, another approach is to analyse long series of observations to check if some changes in the observed extreme rainfall time series were already apparent This note presents a method for trend detection adapted to extreme events and an application to daily extreme precipitation in the Mediterranean area. In the first section we present the study area and the data, in the second section we describe the multivariate regional test, and in the last section, we present and discuss the results of the trend detection in Mediterranean extreme daily rainfall series.

\section{Study area and data}

The study area covers roughly the half of the South of France, including areas with a Mediterranean climate in the area around the Mediterranean Sea but also Mediterranean and mountainous climate, strictly mountainous climate and an area under oceanic influence (Fig. 1). In 2004 we sampled daily rainfall series with at least 56 years of continuous records for this region: 92 series were extracted from the Météo-France (the French national weather service) database. As the study area is larger than the Mediterranean region, a classification of rain gauges in homogeneous regions with regard to extreme rainfall was performed on the basis of the monthly Gumbel's scale parameter, the annual occurrence of extreme events, the elevation of the gauges and the amount of monthly rainfall. The hierarchical clustering algorithm of Ward (Saporta, 2006) was applied and led to the

Published by Copernicus Publications on behalf of the European Geosciences Union. 


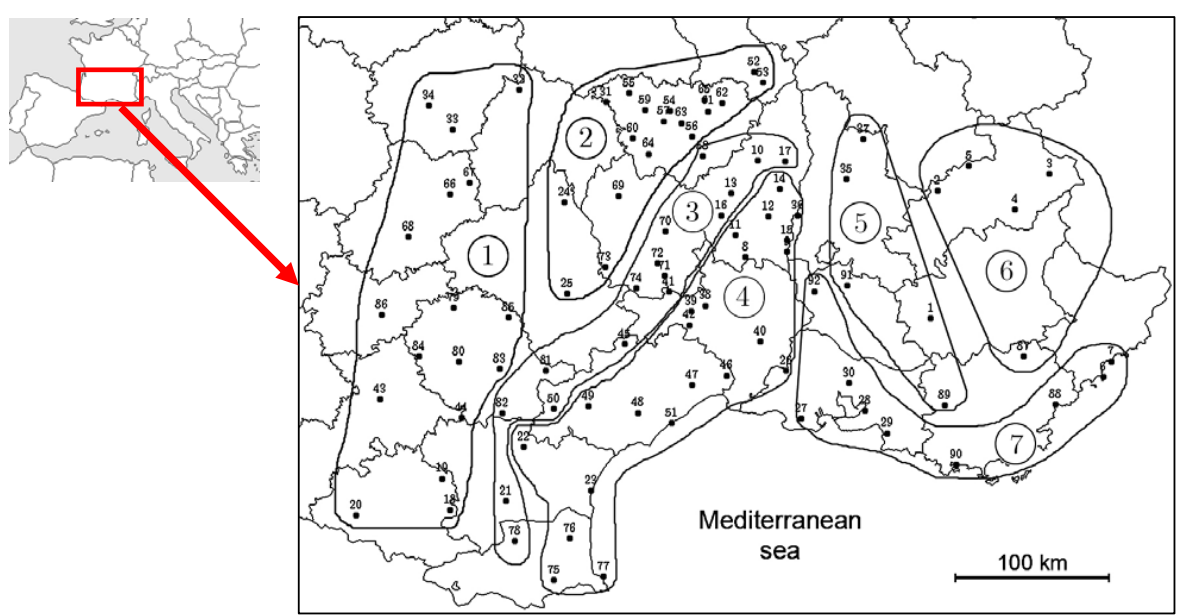

Fig. 1. Study area with the seven homogeneous zones and the location of the 92 daily rain gauges.

seven "homogeneous" regions presented in Fig. 1. Zones 4 and 7 have a Mediterranean climate, zone 3 has a mountainous Mediterranean climate, zones 1 and 2 are mainly under oceanic influences, and zones 5 and 6 have a mountainous climate. We focused mainly on the first four zones containing from 16 to 22 gauges, because in zones 5 to 7 the spatial density of gauges was much lower. For each zone, we sampled Annual Daily Maximum (ADM) rainfall and also the annual maximum rainfall that lasted 2 and 3 days.

\section{The multivariate regional test for trend detection}

A multivariate regional test for trend detection was developed. Why a regional test? Several authors have already underlined the difficulty to interpret at large scales (the region or the catchment) changes detected at the local scale (Spagnoli et al., 2002; Svensson et al., 2005). Take for example a set of 20 gauges. We would like to check if a trend could be detected for a given time series at each gauge with a local trend detection test with a risk level of 5\%. For example, take the most widely-used Mann-Kendall test for trend (Kendall, 1975). Suppose that only one significant trend is detected and for the 19 other gauges the test finds no significant trend. One out of 20 is 5\%, exactly the risk level of our test. This means we have a 5\% chance of rejecting the stationary assumption, whereas in fact it is true. So what can we conclude? Have we identified a significant climatological signal or is our result simply due to chance? The regional approach aims to answer this question known as the regional significance of the test (Renard et al., 2008). Regional approaches can be classified in two groups (i) the first group requires building a regional statistics of local tests, see for example Douglas et al. (2000) for the Mann-Kendall test, (ii) the second group requires defining a regional variate which is analysed with the classical local test for example (Pujol et al., 2007). But in both cases, the spatial dependence between gauges may create redundant information that must be taken into account. The aim of the multivariate test is to assess the spatial consistency. The test described here was developed for annual rainfall maxima and is based on the four following steps. We considered a homogeneous region, with $\mathrm{m}$ gauges. Let $\mathrm{X}_{j}$ be the ADM rainfall at gauge $j$.

\subsection{The definition of a model for ADM rainfall}

According to the extreme value theory, the marginal distribution of $\mathrm{X}_{j}$ is a Generalized Extreme Value (GEV) distribution with position and scale parameter, respectively $\mu_{j}$ and $\sigma_{j}$, depending on the gauge and the shape parameter $\xi$ which is assumed to be constant for $N$ gauges in the region. The probability distribution function (pdf) is given by Eq. (1):

$$
\begin{aligned}
& \operatorname{GEV}_{j}(\mathrm{x})=u_{j}=\operatorname{Prob}\left(\mathrm{X}_{j} \leq \mathrm{x}\right) \\
& =\exp \left(-\left(1+\frac{\xi\left(\mathrm{x}-\mu_{j}\right)}{\sigma_{j}}\right)^{-\frac{1}{\xi}}\right)
\end{aligned}
$$

The spatial dependency between the $N$ gauges is modelled with a joint distribution $F$, which is defined with the copula function by Eq. (2):

$$
\begin{aligned}
& F\left(\mathrm{x}_{1}, \mathrm{x}_{2}, \ldots, \mathrm{x}_{m}\right)=\operatorname{prob}\left[\mathrm{X}_{1}<\mathrm{x}_{1}, \ldots, \mathrm{X}_{m}<\mathrm{x}_{m}\right] \\
& =C\left(F_{1}\left(\mathrm{x}_{1}\right), \ldots, F_{m}\left(\mathrm{x}_{m}\right)\right)
\end{aligned}
$$

$C$ is the copula function that describes the spatial dependence structure between $N$ gauges. Different copula functions exist and are described for example in Favre et al. (2004). In our case, extreme copulas should be used (Salvadori et al., 2007) but they are difficult to handle in the multivariate case. Consequently we used the Student copulas parameterised by a dependence matrix $\Sigma$ and a degree of freedom $v$. This enables us to model heavy tail dependence for small values 
of $v$ and Gaussian dependence structure for larger values of $v$. The mathematical expression of the Student copulas can be found for example in Favre et al. (2004), Cherubini et al. (2004) and Pujol (2007).

\subsection{Definition of the models: the stationary case (M0) and the model with a trend (M1)}

The models are based on the following three assumptions (a) the trend is linear (b) the trend affects the position parameter of the GEV distributions, which means that we focus on a change in the mean of the $\mathrm{X}_{j}$ distribution and (c) the trend is assumed to be the same for all the gauges in a given geographical zone.

Thus the two models are given by Eq. (3):

$$
\begin{aligned}
& \text { M0: } \mathrm{X}_{j} \sim \operatorname{GEV}_{j}\left(\mu_{j}, \sigma_{j}, \xi\right), \operatorname{pour} j=1 / m \\
& \text { M1: } \mathrm{X}_{j} \sim \operatorname{GEV}_{j}\left(\mu_{j}(1+\delta t), \sigma_{j}, \xi\right), \operatorname{pour} j=1 / m
\end{aligned}
$$

where $\delta$ is the regional trend

The dependence matrix $\Sigma$ between the $m$ gauges is given by Eq. (4). The correlation coefficient between two gauges $i$ and $j$ is assumed to decrease exponentially according to the distance between gauges $i$ and $j$, denoted $d_{i j}$. The two positive parameters of the correlogram function are $\gamma_{0}$ and $\gamma_{1}$.

$\Sigma=\left(\begin{array}{cccc}1 & \rho_{12} & \ldots & \rho_{1} m \\ 1 & & \rho_{2} m \\ & \ddots & \vdots \\ & & 1\end{array}\right)$ where $\rho_{i j}=\gamma_{0} \exp \left(-\gamma_{1} d_{i j}\right)$

Model M0 has 2 local parameters and 3 regional ones, and model M1 has one additional regional parameter.

\subsection{Parameter estimation}

This step is based on the maximisation of the likelihood function $L$. With the previous steps, this function is defined for model M1 by Eq. (5):

$$
\begin{aligned}
& L\left(\mathrm{X}_{1}, \ldots, \mathrm{X}_{m}, \boldsymbol{\sigma}, \boldsymbol{\mu}, \xi, \delta, \gamma_{0}, \gamma_{1}\right) \\
& =\prod_{t=1}^{n} f\left(\mathrm{x}^{t_{1}}, \ldots, \mathrm{x}^{t_{m}}, \boldsymbol{\sigma}, \boldsymbol{\mu}, \xi, \delta, \gamma_{0}, \gamma_{1}\right)
\end{aligned}
$$

where $f$ is the multivariate density function for year $t$, given by Eq. (6) :

$$
\begin{aligned}
& f\left(\mathrm{x}^{t_{1}}, \ldots, \mathrm{x}^{t_{m}}, \boldsymbol{\sigma}, \boldsymbol{\mu}, \xi, \delta, \gamma_{0}, \gamma_{1}\right)=\left(\prod_{j=1}^{m} \operatorname{gev}_{j}\left(\mathrm{x}^{t_{j}}\right)\right) \\
& \times c_{\Sigma}\left(\mathrm{GEV}_{1}\left(\mathrm{x}^{t_{1}}\right), \ldots, \operatorname{GEV}_{m}\left(\mathrm{x}^{t_{m}}\right)\right)
\end{aligned}
$$

$\operatorname{gev}_{j}(\mathrm{x})$ is the density probability function of the GEV at gauge $j, c_{\Sigma}$ is the Students copula density, and $\boldsymbol{\mu}$ and $\sigma$ are the column vectors of respectively the position and scale parameters of the $m \mathrm{GEV}$.

\begin{tabular}{|c|c|c|c|c|c|c|}
\hline Zone 1 & Zone 2 & Zone 3 & Zone 4 & Zone 5 & Zone 6 & Zone 7 \\
\hline ST & ST & ST & \multirow{2}{*}{\multicolumn{4}{|c|}{ No significant trend }} \\
\hline$\delta=4 \%$ & $\delta=7 \%$ & $\delta=8 \%$ & & & & \\
\hline
\end{tabular}

A genetic algorithm (Chatterjee et al., 1996) was used to maximise the likelihood function (Eq. 5).
Table 1. Result of the regional multivariate test for trend detection in the ADM rainfall, ST indicates a significant trend at the $10 \%$ risk level, and $\delta$ is the trend value.

\subsection{Selection of the "best" model between M0 and M1}

We used the likelihood ratio test presented in Coles (2001). This test is a tool for choosing the best of two nested models. The latter property can easily be demonstrated in our case: M0 is nested in M1 because we obtained M0 while taking a special value of the parameter in M1, by annealing $\delta$.

\section{Application to Mediterranean extreme rainfall series}

The previous test was applied to the ADM rainfall of the seven zones described in Sect. 2. The regional multivariate test detected a significant trend at the $10 \%$ risk level for three out of the seven zones (Table 1). The trend mainly concerns the mountainous area around the west part of the Mediterranean Sea: The Pyrenees, the south of the Massif Central and the Cevennes region. The trend is significant, but as the position parameter of the ADM rainfall distribution increased by at least 10\% during the 1949-2004 observation period, the trend is slight. This means that, between 1949 and 2004, each ADM rainfall quantile of the three zones also increased by from $4 \%$ to $10 \%$, depending on the zone. The same results were obtained for annual rainfall maxima cumulated over 2 or 3 days. This trend is lower than the one obtained by a regional test without modelling spatial dependence (Pujol et al., 2007).

\section{Conclusions}

We present a tool for the detection of trends in extreme value time series that take the spatial consistency into account. A slight but significant trend was observed in ADM rainfall series in the mountainous area around the Mediterranean Sea during the 1949-2004 period. This is only a descriptive study and the results thus need to be interpreted. Indeed, as our observation period is only 56 years long, one could ask if this trend is related to a climatological signal or is only due to the natural variability of extreme rainfall particularly in the Mediterranean region? If this is the case, as an extrapolation of this trend in the future is not founded, how could this trend evolve in the future? These questions are currently being analysed in an ongoing work, which aims to identify the 
main atmospheric patterns related to extreme rainfall at different spatial scales. The selected patterns will then be used as covariates instead of time as in the test presented here. The projected patterns made by climate models for middle and long terms in different $\mathrm{CO}_{2}$ emission scenarios should then allow us to estimate the ADM rainfall distribution in the future.

Acknowledgements. The authors thank Météo-France for providing meteorological data.

Edited by: M.-C. Llasat

Reviewed by: one anonymous referee

\section{References}

Chatterjee, S., Laudato, M., and Lynch, L. A.: Genetic algorithms and their statistical applications: An introduction, Comput. Stat. Data An., 22, 633-651, 1996.

Cherubini, U., Luciano, E., and Vecchiato, W.: Copula Method in Finance, Wiley Finance, 308 p., 2004.

Coles, S.: An introduction to statistical modelling of extreme values, Springer, 208 p., 2001.

Douglas, E. M., Vogel, R. M., and Kroll, C. N.: Trends in flood and low flows in the United States: Impact of spatial correlation, J. Hydrol., 240, 90-105, 2000.

Favre, A. C., El Aldouni, S., Perreault, L., Thiémonge, N., and Bobée, B.: Multivariate hydrological frequency analysis using copulas, Water Resour. Res., 40, W01101, doi:10.1029/2003WR002456, 2004.
IPCC: Climate Change: Synthesis Report, An Assessment of Intergovernmental Panel on Climate Change, 2007.

Kendall, M. G.: Rank correlation methods, Griffin, London, 202 p., 1975.

Pujol, N.: Développement d'approches régionales et multivariées pour la détection de non stationnarités d'extrêmes climatiques, Applications aux précipitations du pourtour méditerranéen français, PhD Thesis, Université Montpellier I et II, France, 2008.

Pujol, N., Neppel, L., and Sabatier, R.: Approche régionale pour la détection de tendances dans des séries de précipitations de la région méditerranéenne française, Cr. Acad. Sci. II A, C. R. Geosci., 339, 651-658, 2007.

Renard, B., Lang, M., Bois, P., Dupeyrat, A., Mestre, O., Niel, H., Sauquet, E., Prudhomme, C., Parey, S., Paquet, E., Neppel, L., and Gailhard, J.: Regional Methods for trend detection: assessing field significance and regional consistency, Water Resour. Res., 44, W08419, doi:10.1029/2007WR006268, 2008.

Salvadori, G., De Michele, C., Kottegoda, N. T., and Rosso, R.: Extremes in Nature, An approach using Copulas, Water Sciences and Technology Library Series, Springer, 56, 2007.

Saporta, G.: Probabilités, analyse de données et statistique, Technip, 622 p., 2006.

Spagnoli, B., Planton, S., Deque, M., Mestre, O., and Moisselin, J. M.: Detecting climate change at regional scale: the case of France, Geophys. Res. Lett., 29(10), 1450, doi:10.1029/2001GL014619, 2002.

Svensson, C., Kundzewicz, Z. W., and Maurer, T.: Trend detection in river flow series: 2. Flood and low flow index series, Hydrolog. Sci. J., 50(3), 811-824, 2005. 